\title{
Management of knee osteoarthritis in primary care
}

\author{
Hui Shan Sim ${ }^{1}$, MD, GDFM, Ke Xin Magneline Ang $^{2}$, MBBS, Choon How How ${ }^{1}$, MMed, FCFP,
} Sir Young James $\underline{L O}^{2}$, FRCSEd, MBBS

\begin{abstract}
Alice, a 62-year-old homemaker, went to your clinic for her routine follow-up for diabetes mellitus and chronic kidney disease (CKD) Stage 3. You advised exercise, as her diabetic control was suboptimal despite her good diet control. She sniggered and pointed to her knees. You noticed bony swelling of her knees and subsequently found out that she has been having knee pain for the last few months and weight gain due to reduction in activity. When you asked her whether she had been taking painkillers for her knees, she said you had previously advised her to be careful with painkillers in view of her CKD.
\end{abstract}

\section{WHAT IS OSTEOARTHRITIS OF THE KNEE?}

Osteoarthritis $(\mathrm{OA})$ of the knee is one of the most common chronic inflammatory joint diseases, and its prevalence increases with age. It is degeneration of the joint secondary to a multitude of causes such as infection, trauma and systemic inflammatory conditions such as gout. Patients often experience pain, joint stiffness, swelling and restriction in mobility. Symptoms may not correlate with radiological changes. Some patients may have significant pain without many arthritic changes on radiography, and vice versa.

Knee OA often leads to gradual adaptation to symptoms and can result in functional and psychological problems such as weakness, poor balance, inability to fulfil work or recreational needs, and poor sleep and mood.

\section{HOW RELEVANT IS THIS TO MY PRACTICE?}

In 2015-2016, 2.6 out of every 100 Australian general practitioner encounters were for OA. ${ }^{(1)}$ One study found that the lifetime risk of symptomatic knee OA was $>40 \%{ }^{(2)}$ About $25 \%$ of patients with symptomatic knee $O A$ have difficulties with major activities of daily living such as walking $400 \mathrm{~m}$, climbing stairs and stooping. ${ }^{(3)}$ These numbers are expected to rise in view of the ageing population, increasing obesity and more sedentary lifestyles.

Data shows that knee OA as a chronic disease is not well managed. Many patients are not receiving the appropriate care based on guidelines and are referred for surgery before optimisation of conservative management.

Knee OA can also be a cause or an effect of other chronic diseases such as obesity. Patients have an increased risk of allcause mortality, especially due to cardiovascular disease. ${ }^{(4)}$ Hence, it is pertinent to screen and treat it early and well to optimise care for patients and maximise their mobility and independence.

\section{WHAT CAN I DO IN MY PRACTICE?}

The goal of knee OA management is to help patients manage their symptoms, maximise function and slow disease progression via patient self-empowerment.

\section{Establishing the diagnosis}

The typical knee OA patient is aged $>45$ years and has mechanical pain, morning stiffness of less than 30 minutes $^{(5,6)}$ and functional limitation. ${ }^{(7)}$ There is often crepitus, bony enlargement and restricted range of motion, ${ }^{(7)}$ and the joint can be warm during an OA flare. Knee OA involves both knees, but one is usually more symptomatic than the other. The following findings may constitute red flags or suggest further workup to rule out other differential diagnoses (e.g. septic arthritis and inflammatory conditions): young age, effusion, ${ }^{(6,8)}$ signs of infection, inflammatory arthritides, cancer, fracture, ${ }^{(9)}$ rapid rate of worsening ${ }^{(5)}$ and severe pain. ${ }^{(8)}$ Box 1 shows typical features and red flags.

\section{Self-management and non-pharmacological strategies}

The most useful strategy in knee OA management is a combination of self-empowerment, weight loss and/or exercise (Table I). ${ }^{(5,6,10,11)}$

Patients should be equipped with knowledge, understanding, treatment options and resources for OA. The physician should guide them to define their own priorities of treatment and outcome as well as to cope and problem solve so that they can direct their own treatment. Nevertheless, not all patients can self-manage well; those with poor coping skills or intellectual impairment may need more assistance. More frequent follow-up can be considered for such patients as well as patients with more severe knee OA or those on medications or with comorbidities.

One of the most helpful treatments is weight loss in overweight patients. Weight loss of $5 \%-10 \%$ in six months can lead to significant improvements in function and pain. ${ }^{(12,13)}$ Weight issues can lead to a vicious cycle, with overweight patients suffering from arthritis and patients with arthritis reducing activity

${ }^{1}$ Care and Health Integration, ${ }^{2}$ Orthopaedic Surgery, Changi General Hospital, Singapore

Correspondence: DrSim Hui Shan, Resident Physician, Care and Health Integration, Changi General Hospital, 2 Simei Street 3, Singapore 529889. Hui_Shan_Sim@cgh.com.sg 
Box 1. Diagnosing osteoarthritis (OA) of the knee: Typical knee OA features

Symptoms:

- $>45$ years of age

- Mechanical joint pain

- Morning stiffness $<30$ minutes

- Functional limitation

Physical findings:

- Crepitus

- Bony enlargement

- Restricted range of motion

- Joint is not 'hot'

Red flags

- Young age

- Effusion

- Rapid rate of worsening

- Severe pain

- Signs of:

- Infection

- Inflammatory arthritides

- Cancer

- Fracture

and putting on weight. One practical advice in relation to weight is for patients to reduce the carrying of heavy loads such as bags.

Knee strengthening and aerobic exercises ${ }^{(5,11,14)}$ and exercise plans with progressive goals ${ }^{(14)}$ have been found to be efficacious. A useful resource for knee strengthening exercises is the Royal Australian College of General Practitioners (RACGP) Handbook of Non-Drug Interventions (HANDI) website. If patients do not improve with self-directed exercising, supervised exercise sessions at community rehabilitation centres or polyclinics can be considered. ${ }^{(10)}$ However, they should avoid exercises involving heavy load and high-impact exercises such as jumping, climbing and running.

Patients may need to modify their lifestyle to circumvent the limitations posed by having arthritic knees. This includes using a lift (if available) instead of a staircase. The walking distance needs to be tolerable by the arthritic knee and not exacerbate the condition.

Accompanying issues such as mood, sleep and gait-related problems such as instability should be managed, as these can exacerbate symptoms and severity of knee OA. For patients with a prominent psychological component contributing to symptoms, psychotherapy such as cognitive behavioural therapy ${ }^{(6,10)}$ and the painTRAINER.org website may be helpful.

With regard to supplements, later analyses of glucosamine and chondroitin studies suggest that perhaps only non-generic, prescription-grade crystalline glucosamine sulfate at $1,500 \mathrm{mg}$ daily or pharmaceutical-grade chondroitin sulfate 800-1,200 mg/day may be effective. ${ }^{(6,11)}$ Avocado soybean unsaponifiables ${ }^{(11)}$ and other herbal and supplement therapies still do not have robust evidence supporting their use. ${ }^{(6)}$

Other non-pharmacological considerations include footwear, walking aid and heat therapy. ${ }^{(5,6,10)}$ Knee bracing, taping and insoles are more controversial and may help when directed by the healthcare practitioner. ${ }^{(5,6,10)}$

\section{Pharmacological management}

Nonsteroidal anti-inflammatory drugs (NSAIDs) may be the most effective pharmacological treatment for OA knee pain. However, they are known to cause renal impairment, cardiovascular and bleeding gastrointestinal (Gl) tract risks, and rise in blood pressure. Topical NSAIDs are safer and may be as effective as oral NSAIDs. ${ }^{(11)}$ One meta-analysis suggested that diclofenac and piroxicam patches may be the most effective topical NSAIDs for pain and function, respectively. ${ }^{(15)}$ Among the NSAIDs studied, celecoxib $200 \mathrm{mg} /$ day may pose the lowest Gl and cardiovascular risks. ${ }^{(11)}$ Several professional organisations recommend prescribing proton pump inhibitor with NSAIDs. ${ }^{(5,11)}$ It is prudent to avoid NSAIDs in patients with chronic kidney disease (CKD) Stage 3-5 and cardiac disease.

Recent evidence shows that paracetamol is not very effective for OA knee pain ${ }^{(5,6,10,11)}$ and also causes a dose-response increase in complications such as liver injury, renal impairment, cardiovascular events, and gastrointestinal perforation, ulceration and bleeding. ${ }^{(11)}$ Taking paracetamol for at least 22 days per month or 6-14 tablets per week was noted to predispose people to more cardiovascular events. ${ }^{(16)}$

Opioids are not recommended for use in knee OA in view of their limited efficacy and concerns regarding side effects and dependence. ${ }^{(6,10)}$ The use of duloxetine is still controversial..$^{(6,10,11)}$

As always, the aim is to reduce analgesia to the lowest effective dose for the shortest duration to minimise risk of complications from the drug.

\section{Interventional treatment}

Intra-articular glucocorticoids ${ }^{(5,6,10,11)}$ can be considered, although they may also affect patients' blood glucose and blood pressure and result in increased cartilage loss. If repeated injections are needed, it is prudent to refer the patient to a specialist.

Viscosupplementation via intra-articular hyaluronic $\operatorname{acid}^{(5,6,10,11,17)}$ has been offered by some general practitioners and specialists in private practice. There is scepticism about the clinical benefit ${ }^{(6)}$ of viscosupplementation although the American Medical Society for Sports Medicine has released a scientific statement advocating its benefits for well-selected patients. ${ }^{(17)}$ Alternative treatments such as acupuncture and transcutaneous electrical nerve stimulation (i.e. TENS) are controversial. ${ }^{(5,6,10)}$ Arthroscopy for lavage and debridement is no longer advised for knee OA except for selected patients, ${ }^{(5,6,9)}$ and prognosis is guarded with arthroscopic procedures.

In patients with severe tricompartmental OA and functional impairment, primary total knee arthroplasty (TKA) is an effective procedure. Prosthetic survival rates have improved over the years, ranging from $85 \%$ to $90 \%$ at 15 years in several long-term studies performed on patients aged 55 years or younger with less functionally demanding lifestyles. ${ }^{(18,19)}$ The option of jointpreserving surgical options such as high tibial osteotomy and distal femoral osteotomy needs to be considered where applicable. Osteotomy is preferable for younger patients aged below 60 years who develop unicompartmental (medial/lateral) OA due to high activity level. It serves to re-align the mechanical axis of the limb 
Table I. Treatment for osteoarthritis of the knee.

\begin{tabular}{|c|c|}
\hline Treatment & Remarks \\
\hline \multicolumn{2}{|l|}{ Non-pharmacological treatment } \\
\hline $\begin{array}{l}\text { Self-management: } \\
\text { - Equip patients with knowledge, understanding, treatment } \\
\text { options and resources } \\
\text { - Guide them to define own priorities of treatment and outcome } \\
\text { and how to self-cope and problem solve }\end{array}$ & Most important. \\
\hline $\begin{array}{l}\text { Weight loss } \\
\text { - Aim for }>5 \%-10 \% \text { loss in } 6 \text { months }\end{array}$ & Useful in overweight patients. Consider reducing external loads (e.g. bags). \\
\hline $\begin{array}{l}\text { Exercises (e.g. knee strengthening and low-impact aerobic } \\
\text { exercises) }\end{array}$ & $\begin{array}{l}\text { - Physiotherapy resources (e.g. RACGP HANDI). } \\
\text { - Avoid joint trauma, heavy loads, climbing, jumping. } \\
\text { - Non-impact exercises such as swimming and walking are suitable. } \\
\text { Cycling may not be feasible for every patient. }\end{array}$ \\
\hline \multicolumn{2}{|l|}{ Correct footwear, walking aid } \\
\hline Psychotherapy & Includes online resources (e.g. painTRAINER.org). \\
\hline \multicolumn{2}{|l|}{ Pharmacological treatment } \\
\hline \multicolumn{2}{|l|}{ Topical NSAIDs } \\
\hline Paracetamol & $\begin{array}{l}\text { - Often not efficacious. } \\
\text { - Recent studies highlight dose-related safety concerns, including Gl, } \\
\text { renal, liver and CV side effects. }\end{array}$ \\
\hline Oral NSAIDs & $\begin{array}{l}\text { - Avoid in CKD Stage 3-5 and cardiac patients. } \\
\text { - Risk of renal impairment, CV, bleeding GI complications and rise in blood } \\
\text { pressure. } \\
\text { - Consider proton pump inhibitor to mitigate risk of Gl bleeding. }\end{array}$ \\
\hline \multicolumn{2}{|l|}{ Interventional management } \\
\hline Intra-articular glucocorticoid & $\begin{array}{l}\text { - Affects blood glucose and blood pressure. } \\
\text { - Refer if patient needs }>3 \text { administrations of intra-articular } \\
\text { glucocorticoid spread out over one year. } \\
\text { - Risk of septic arthritis if strict aseptic technique is not observed. }\end{array}$ \\
\hline Viscosupplementation via intra-articular hyaluronic acid & $\begin{array}{l}\text { - Still a controversial treatment. Outcome may differ for the individual. } \\
\text { - Risk of septic arthritis if strict aseptic technique is not observed. }\end{array}$ \\
\hline Arthroscopy for lavage and debridement & $\begin{array}{l}\text { - Only for selected patients. } \\
\text { - Prognosis is guarded. }\end{array}$ \\
\hline Surgery (including knee arthroplasty and osteotomies) & $\begin{array}{l}\text { - Consider after } 3 \text { months if optimised conservative management fails. } \\
\text { - Start pre-surgery optimisation of patient's weight, knee muscles and } \\
\text { fitness for surgery to improve surgical outcome. }\end{array}$ \\
\hline
\end{tabular}

CKD: chronic kidney disease; CV: cardiovascular; GI: gastrointestinal; NSAIDs: nonsteroidal anti-inflammatory drugs; RACGP HANDI: Royal Australian College of General Practitioners Handbook of Non-Drug Interventions

to offload the painful arthritic compartment of the knee joint. High tibial osteotomy or distal femoral osteotomy can be performed for varus or valgus knees, respectively. This may delay the need for a total knee arthroplasty in a young patient for 5-10 years, ${ }^{(20-22)}$ provided there is lifestyle modification after such surgeries.

Alternatively, patients with only medial or lateral knee OA and low functional demands may consider unicondylar knee arthroplasty. Patellofemoral OA can also be managed with patellofemoral arthroplasty. Implant survival rates of $75 \%-90 \%$ at 10 years have been reported in various studies. ${ }^{23,24)}$ Subsequent progression of OA in other compartments may necessitate revision with TKA.

Prior to surgery, primary care physicians can counsel and prepare patients by informing them about the risks and benefits of surgery, telling them what to expect and optimising their fitness for surgery. We can advise and facilitate weight loss and knee muscle strengthening before knee replacement surgery to improve surgical outcomes. Postoperatively, patients are often allowed to start active weight-bearing and range of motion exercises within 24 hours under the guidance of a physiotherapist. They may be discharged home within five days should recovery be uneventful. Alternatively, they can be transferred to a community hospital for further inpatient rehabilitation. On discharge, regular outpatient follow-up with the orthopaedic specialist will be scheduled to monitor their progress.

\section{WHEN SHOULD I REFER TO A SPECIALIST?}

Referral to target specific areas of concern can be considered, such as dietetics and weight management clinic for overweight patients, and physiotherapy for patients who have difficulty finding an exercise regimen that they can cope with. Physicians can consider referring patients to surgeons if a justified attempt at conservative management of at least three months ${ }^{(5)}$ fails to address their needs. While there is no recommended age for surgery, a rule of thumb is that surgery is recommended for those who are older 
than 50 years of age with a sedentary lifestyle. A balance should be struck between undergoing surgery before patients become too deconditioned or homebound to reap its benefits and the higher rates of revision surgery in younger and more active patients. It is important that patients considering surgery are adequately optimised to reduce the recovery period. As a number of patients with knee OA suffer from deconditioning, their recovery is likely to be prolonged without adequate preoperative physiotherapy.

\section{CONCLUSION}

OA of the knee is a very common chronic disease that can have a great impact on patients, mood, function at work and daily life. The main evidence-based conservative treatments are weight loss, knee strengthening and low-impact aerobic exercises, NSAIDs and intra-articular glucocorticoids. However, treatment is often not optimised before referral for surgery.

\section{TAKE HOME MESSAGES}

1. Knee OA can be clinically diagnosed in the absence of atypical findings such as young age, effusion, signs of infection, inflammatory arthritides and severe pain.

2. Consider appropriate referrals for weight loss and physiotherapy to help optimise conservative management. One resource for knee strengthening exercises is the RACGP HANDI website.

3. Avoid oral NSAIDs in patients with CKD and cardiac conditions. NSAIDs can worsen CKD, especially in the setting of chronic pain conditions such as knee OA. Proton pump inhibitors can mitigate the risk of GI bleed with NSAIDs.

4. Consider surgical referral if three months of optimised conservative management does not address the needs of the patient. As implant survival rates have greatly improved, surgery should be considered before the onset of functional decline and social isolation.

You advised paracetamol, topical nonsteroidal anti-inflammatory drugs and tramadol for Alice's severe pain. You also gave her a website link for knee strengthening exercises and recommended a short trial of analgesia before she exercised with her friends. When Alice returned three months later, you noticed some improvement in her weight and glycated haemoglobin level. She reported that her knee pain was better and that she was happier because she was sleeping better and able to participate in activities with her friends again. She intended to continue doing the exercises to help with her pain and weight.

\section{REFERENCES}

1. Britt H, Miller GC, Henderson J, et al. General practice activity in Australia 2015-16. General practice series no. 40. Sydney: Sydney University Press, 2016.

2. Murphy L, Schwartz TA, Helmick CG, et al. Lifetime risk of symptomatic knee osteoarthritis. Arthritis Rheum 2008; 59:1207-13.

3. Arthritis Foundation, Centers for Disease Control and Prevention. A National Public Health Agenda for Osteoarthritis 2010. Available at: https://www.cdc. gov/arthritis/docs/OAagenda.pdf. Accessed May 15, 2020.

4. Palazzo C, Nguyen C, Lefevre-Colau MM, Rannou F, Poiraudeau S. Risk factors and burden of osteoarthritis. Ann Phys Rehabil Med 2016; 59:134-8.

5. National Institute for Health \& Clinical Excellence. Osteoarthritis: care and management. Clinical guideline [CG177]. London: National Institute for Health \& Clinical Excellence, 2014.

6. Royal Australian College of General Practitioners. Guideline for the management of knee and hip osteoarthritis. Second edition. East Melbourne: RACGP, 2018.

7. Zhang W, Doherty M, Peat G, et al. EULAR evidence-based recommendations for the diagnosis of knee osteoarthritis. Ann Rheum Dis 2010; 69:483-9.

8. Martel-Pelletier J, Maheu E, Pelletier JP, et al. A new decision tree for diagnosis of osteoarthritis in primary care: international consensus of experts. Aging Clin Exp Res 2019; 31:19-30.

9. British Association of Knee Surgery, British Orthopaedic Association, Royal College of Surgeons of England. 2017 Commissioning Guide: Painful Osteoarthritis of the Knee. Available at: https://www.rcseng.ac.uk/-/media/ files/rcs/standards-and-research/commissioning/boa--painful-oa-knee-guidefinal-2017.pdf. Accessed May 15, 2020.

10. Kolasinski SL, Neogi T, Hochberg MC, et al. 2019 American College of Rheumatology/Arthritis Foundation Guideline for the Management of Osteoarthritis of the Hand, Hip, and Knee. Arthritis Rheumatol 2020; 72:220-33.

11. Bruyère $\mathrm{O}$, Honvo $\mathrm{G}$, Veronese $\mathrm{N}$, et al. An updated algorithm recommendation for the management of knee osteoarthritis from the European Society for Clinical and Economic Aspects of Osteoporosis, Osteoarthritis and Musculoskeletal Diseases (ESCEO). Semin Arthritis Rheum 2019; 49:337-50.

12. Christensen R, Bartels EM, Astrup A, Bliddal H. Effect of weight reduction in obese patients diagnosed with knee osteoarthritis: a systematic review and meta-analysis. Ann Rheum Dis 2007; 66:433-9.

13. Messier SP, Mihalko SL, Legault C, et al. Effects of intensive diet and exercise on knee joint loads, inflammation, and clinical outcomes among overweight and obese adults with knee osteoarthritis: the IDEA randomized clinical trial. JAMA 2013; 310:1263-73

14. Fernandes L, Hagen KB, Bijlsma JW, et al. EULAR recommendations for the non-pharmacological core management of hip and knee osteoarthritis. Ann Rheum Dis 2013; 72:1125-35.

15. Zeng C, Wei I, Persson MSM, et al. Relative efficacy and safety of topical nonsteroidal anti-inflammatory drugs for osteoarthritis: a systematic review and network meta-analysis of randomised controlled trials and observational studies. Br J Sports Med 2018; 52:642-50.

16. Chan AT, Manson JE, Albert CM, et al. Nonsteroidal antiinflammatory drugs, acetaminophen, and the risk of cardiovascular events. Circulation 2006; 113:1578-87.

17. Trojian TH, Concoff AL, Joy SM, et al. AMSSM scientific statement concerning viscosupplementation injections for knee osteoarthritis: importance for individual patient outcomes. Clin J Sport Med 2016; 26:1-11.

18. Duffy GP, Crowder AR, Trousdale RR, Berry DJ. Cemented total knee arthroplasty using a modern prosthesis in young patients with osteoarthritis. J Arthroplasty 2007; 22(6 Suppl 2):67-70.

19. Hofmann AA, Heithoff SM, Camargo M. Cementless total knee arthroplasty in patients 50 years or younger. Clin Orthop Relat Res 2002; (404):102-7.

20. Akizuki S, Shibakawa A, Takizawa T, Yamazaki I, Horiuchi H. The long-term outcome of high tibial osteotomy: a ten- to 20-year follow-up. J Bone Joint Surg Br 2008; 90:592-6.

21. Backstein D, Morag G, Hanna S, Safir O, Gross A. Long-term follow-up of distal femoral varus osteotomy of the knee. J Arthroplasty 2007; 22(4 Suppl 1):2-6.

22. Tang WC, Henderson IJ. High tibial osteotomy: Iong term survival analysis and patients' perspective. Knee 2005; 12:410-3.

23. Choong PF, Dowsey MM. Update in surgery for osteoarthritis of the knee. Int J Rheum Dis 2011; 14:167-74.

24. Pennington DW, Swienckowski JJ, Lutes WB, Drake GN. Unicompartmental knee arthroplasty in patients sixty years of age or younger. J Bone Joint Surg Am 2003; 85:1968-73. 


\section{SINGAPORE MEDICAL COUNCIL CATEGORY 3B CME PROGRAMME} (Code SMJ 202010A)

1. Knee osteoarthritis (OA) often leads to gradual adaptation to symptoms and can result in functional and psychological problems such as weakness, poor balance, inability to fulfil work or recreational needs, and poor sleep and mood.

2. Many knee OA patients do not receive the appropriate care based on guidelines and are referred for surgery before optimisation of conservative management.

3. The typical knee OA patient is aged $>45$ years and has mechanical pain, morning stiffness of more than 30 minutes and functional limitation. There is often crepitus, bony enlargement and restricted range of motion.

4. Red flags or important differential diagnoses for knee OA include young age, effusion, signs of infection, inflammatory arthritides, cancer, fracture, rapid rate of worsening and severe pain.

5. It is acceptable to delay surgery until patients become deconditioned or homebound as rates of revision surgery tend to be higher in younger and more active patients.

6. The most useful strategy in knee OA management is a combination of self-empowerment, weight loss and/or exercise.

7. Patients with poor coping skills or intellectual impairment, those with more severe knee OA, and those on medications or with comorbidities may benefit from more frequent follow-up.

8. $5 \%-10 \%$ weight loss in six months can lead to significant improvements in function and pain.

9. Accompanying issues such as mood, sleep and gait-related problems such as instability do not exacerbate the symptoms and severity of knee OA.

10. Nonsteroidal anti-inflammatory drugs (NSAIDs) do not cause renal impairment, risks of cardiovascular and gastrointestinal tract bleeding, and rise in blood pressure.

11. Several professional organisations recommend prescription of proton pump inhibitor with NSAIDs.

12. NSAIDs should be avoided in patients with chronic kidney disease Stage 3-5 and cardiac disease.

13. Recent evidence shows that paracetamol is effective for $O A$ knee pain but causes a dose-response increase in complications such as liver injury, renal impairment, cardiovascular events, and gastrointestinal perforation, ulceration and bleeding.

14. Opioids offer limited efficacy for OA knees, and there are concerns regarding side effects and dependence.

15. If repeated intra-articular glucocorticoid injections are needed, it is prudent to refer the patient to a specialist.

16. There is scepticism about the clinical benefit of viscosupplementation although the American Medical Society for Sports Medicine released a scientific statement advocating its benefits for well-selected patients.

17. Prosthetic survival rates have improved over the years, ranging from $85 \%$ to $90 \%$ at 15 years in studies performed on patients aged 55 years or younger with functionally demanding lifestyles.

18. Osteotomies may delay the need for a total knee arthroplasty in a young patient for 5-10 years provided there is lifestyle modification after such surgeries.

19. Physicians should advise and facilitate weight loss and knee muscle strengthening before knee replacement surgery to improve surgical outcomes.

20. Patients cannot start active weight-bearing and range of motion exercises within 24 hours of surgery.

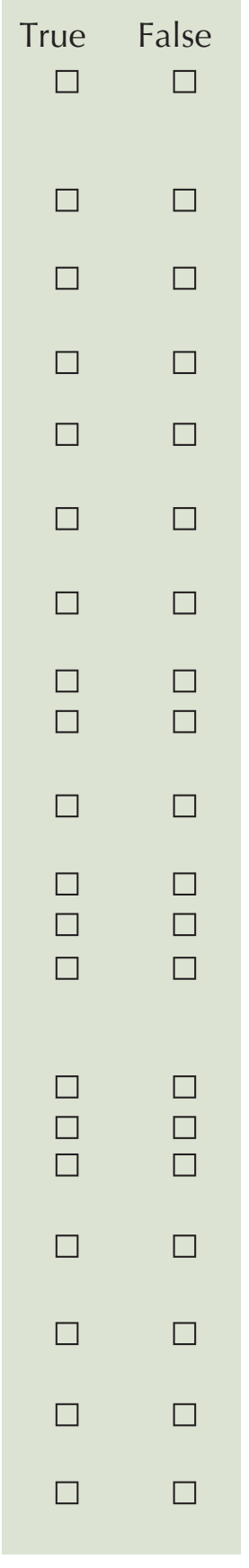

\section{Doctor's particulars:}

Name in full:

Specialty:
MCR no.:

Email:

\section{SUBMISSION INSTRUCTIONS:}

Visit the SMJ website: http://www.smj.org.sg/current-issue and select the appropriate quiz. You will be redirected to the SMA login page.

For SMA member: (1) Log in with your username and password (if you do not know your password, please click on 'Forgot your password?'). (2) Select your answers for each quiz and click 'Submit'.

For non-SMA member: (1) Create an SMJ CME account, or log in with your SMJ CME username and password (for returning users). (2) Make payment of SGD 21.40 (inclusive of $7 \%$ GST) via PayPal to access this month's quizzes. (3) Select your answers for each quiz and click 'Submit'.

RESULTS:

(1) Answers will be published online in the SMJ December 2020 issue. (2) The MCR numbers of successful candidates will be posted online at the SMJ website by 9 December 2020. (3) Passing mark is $60 \%$. No mark will be deducted for incorrect answers. (4) The SMJ editorial office will submit the list of successful candidates to the Singapore Medical Council.

(5) One CME point is awarded for successful candidates. (6) SMC credits CME points according to the month of publication of the CME article (i.e. points awarded for a quiz published in the October 2020 issue will be credited for the month of October 2020, even if the deadline is in December 2020).

Deadline for submission (October 2020 SMJ 3B CME programme): 12 noon, 2 December 2020. 